\title{
How Does Death Harm the Deceased?
}

Taylor W. Cyr

Forthcoming in John K. Davis, ed., Ethics at the of End of Life: New Issues and Arguments, Routledge; please cite published version.

\section{Introduction}

At the beginning of his great and influential essay, "Death," Thomas Nagel writes, "If death is the unequivocal and permanent end of our existence, the question arises whether it is a bad thing to die" (Nagel 1970: 73). Most of us do in fact believe that death can, at least in some cases, be bad for the one who dies. In other words, most of us think that death can harm the deceased. (Note: I take the expressions the badness of death, on the one hand, and the harm of death, on the other hand, to be roughly equivalent, so I will use these and related expressions interchangeably.) Now, of course, one reason that some of us believe that death can be bad is that some of us believe that death is not the end; some of us believe in an afterlife, where some of those who have died will experience punishments involving suffering (which, we can all agree, would be a bad thing). Others of us share Nagel's assumption that death is the permanent end of our existence, not something we will experience but rather an experiential blank. For the purposes of this chapter, let's assume that Nagel is right about this and that death really is the end. (If you don't share this assumption, you can imagine this chapter as exploring a hypothetical scenario: what would you say about the harm of death if you didn't believe in an afterlife?) Nevertheless, most of us want to say that death is one of the greatest evils that can befall a person. As it turns out, it is quite puzzling to explain how death could harm the deceased, given that the deceased no longer exists, and there are interesting and difficult challenges to the belief that it is even possible for death to harm the deceased. 
Before we continue, however, three clarifications are in order. First, when we talk about the harm or badness of death, we are talking about a state of nonexistence - the state that follows a person's life and that begins when the person has ceased living. We must not confuse death with dying, the latter of which is what happens during the end of a person's life, before the person has died. It is not very puzzling how dying can be bad for a person who is experiencing it, since dying all too often includes suffering. Second, the philosophical issues considered here are concerned with the possibility of death's badness for the deceased and not for, say, the person's loved ones who continue to exist after the person's death. Here again, it is not very puzzling how a person's death can be bad for that person's loved ones, since they will very likely experience suffering as a result. Lastly, in discussing how death harms the deceased, we are going to be concerned with how death can harm the deceased. In other words, our concern is whether or not is it even possible for death to harm the deceased. Thus, even if we decide that death can be bad for the one who dies, we are not thereby committed to the claim that death is always badthat it is bad in every case. It might turn out that death always harms the deceased, but perhaps not. Our concern is how death could harm the deceased.

So, given that death is an experiential blank, can death be bad for the one who dies? There are two main answers to this question in the contemporary philosophical literature on the philosophy of death. The first says that it is possible for death to be bad for the one who dies and that it is bad insofar as it deprives the deceased of goods that would have been enjoyed by that person had the person not died. For obvious reasons, this view is called the deprivation account, and it has several defenders (see, for example, Feldman 1992; Bradley 2009; and Fischer 2009), though the details of their accounts 
vary. If you are like me and find yourself with the belief that death can, at least in some cases, be bad for the one who dies, then the deprivation account may strike you as obviously true, or at least as very plausible. According to the deprivation account, death harms the deceased by taking away opportunities to continue enjoying the goods of life. This might happen by depriving the deceased of potential pleasures, such as the pleasures of eating good food or of listening to music, or it might happen by depriving the deceased of opportunities for certain desires to be satisfied, such as the desire to write a book or to see one's grandchildren graduate college. In any case, according to the deprivation account, death can harm the deceased, and it does so by depriving her of various goods.

The second main answer to the question of whether death can be bad is called Epicureanism, named after Epicurus, an Ancient Greek philosopher, and this view denies, as Epicurus himself did, that death can be bad for the one who dies. On this view, there is no case of death that harms the deceased. Again, if you are like me and find it plausible that death can be bad, then Epicureanism might strike you as obviously false, or at least as very implausible. But it turns out that there are several Epicurean challenges to the deprivation account — arguments for the conclusion that death is never bad for the one who dies. Indeed, in the essay mentioned above, Nagel suggests four potential challenges to the deprivation account (Nagel actually counts them as three, but the second involves two distinct challenges), and the remainder of this chapter will consider both how those four challenges could be regimented into arguments for Epicureanism and also how the deprivation account could respond to each. The first three (the "No-Harm-Done Argument," the "No-Subject Argument," and the "Timing Argument") are suggested by Epicurus himself, and the fourth (the "Symmetry Argument"), which has recently 
generated a lively discussion, is suggested by Lucretius, an Ancient Roman philosopher who was himself an Epicurean. As we consider each argument, I will highlight contributions to this debate from Nagel's classic essay, but I will also discuss, especially in connection with the Symmetry Argument, some more recent developments.

\section{The No-Harm-Done Argument}

The first Epicurean challenge that Nagel mentions concerns whether anything can be bad for someone without being experienced as bad by that person (Nagel 1970: 7576). Epicurus puts the challenge this way in his Letter to Menoeceus: "Accustom yourself to the belief that death is nothing to us. For all good and evil lie in sensation, whereas death is the absence of sensation...Therefore that most frightful of evils, death, is nothing to us" (Long and Sedley 1987: 149-150). On Epicurus's own view, in order for a thing to be evil (or to count as bad for a person), that thing must involve some unpleasant sensation - it must involve some pain. But since, on Epicurus's view, death doesn't involve any pain, he concludes that death cannot be bad for the one who dies. We could put Epicurus's argument, the No-Harm-Done Argument, like this (for discussion of a similar argument, see Feldman 1992, chapter 8):

1) Everything that is bad for a person consists in sensation.

2) A person who has died cannot have any sensations.

3) Therefore, death cannot be bad for the one who dies.

The No-Harm-Done Argument is valid, which is to say that the conclusion (3)follows from the premises (1)-(2). The question we need to ask, then, is: are the premises true? Given our assumption about death being a permanent experiential blank, we are 
committed to the truth of (2); you can't have sensations if you don't exist. So it looks like the deprivation account must somehow deny (1), and this is exactly what Nagel does.

Imagine the following scenario: unbeknownst to you, your closest friends have recently spread lies about you to everyone else you know, including the members of your family and your other close friends, thereby betraying your friendship. Imagine, further, that they have been very careful in spreading the lies behind your back, making sure that you never find out about the lies and that you never notice that anyone treats you differently as a result of having heard the lies about you. Do you think that, in such a case, it would be a bad thing for you that you had been betrayed, even though you won't ever find out about the betrayal or suffer as a result? Most people, I think, would say that this betrayal would be bad for the one betrayed; if so, however, then premise (1) must be false, for we've found a case in which something is bad for a person without consisting of sensation. In other words, if it can be bad for you that your friends spread lies behind your back without you ever finding out, then something can be bad for you even though you never have any unpleasant sensations - you never find out about the lies and thus never feel any pain. Nagel argues that such cases are indeed bad (Nagel 1970: 76-78), and thus he would say that premise (1) must be false; there can be bads (or harms) that befall us without our experiencing them as bad. It looks, then, as though the deprivation account has an adequate response to the No-Harm-Done Argument.

Now, of course, one response on behalf of Epicureanism is to deny that this case of betrayal really is bad for the one who is betrayed but never finds out about it. I do not find this response very plausible, but I suppose that Epicureans could dig in their heels on this point. It is worth noting, though, that this would be a very striking result, for there are 
many cases in which we take something to be bad for someone who never experiences the thing as bad, such as when a person's right to privacy is violated without that person's knowledge (Nozick 1999). (For a discussion of this and similar cases, see Fischer 2009, chapter 1, and also Fischer 2014.) For this reason, I don't find this response very plausible. A different Epicurean response, however, would be to argue that the betrayal case is not relevantly similar to the case of death. An Epicurean might argue as follows. In the betrayal case, it is at least possible for the one betrayed to discover what's happened and thus experience the badness of being betrayed; but in the case of death, it is not even possible for the deceased to have any experience of the supposed badness of death; thus (the Epicurean concludes), even if the betrayal really is bad for the one betrayed, it doesn't follow that death can be bad for the deceased.

How might someone defending the deprivation account respond? One way is to construct another case - one in which a person is harmed even though it isn't possible for the person to experience the harm. John Martin Fischer aims to do exactly this in his modified version of the betrayal case:

You are betrayed behind your back by people who you thought were good friends, and you never actually find out about this or have any bad experiences as a result of the betrayal. But now suppose that these friends were (very) worried that you might find out about the betrayal. In order to guard against this possibility, they arrange for White to watch over you. His task is to prevent you ever from finding out about the betrayal. So, for example, if one of the individuals who betrayed you should decide to tell you about it, White can prevent him from succeeding: 
White can do whatever is required to prevent the information from getting to you. (Fischer 2009: 39)

In the modified version of the betrayal case, it is not possible (in the relevant sense) for you to find out about the betrayal because White ensures that this information never reaches you. Still, it certainly seems like this case of betrayal is bad for you, despite the fact that it isn't possible for you to experience the betrayal as bad. And this case is more similar to the case of death; in both the modified betrayal case and the case of death, it is not possible for the person to experience the relevant items (betrayal, on the one hand, and death, on the other) as bad. But, the proponent of the deprivation approach could say, if we accept that the betrayal is bad for you, despite the impossibility that you experience it as bad, then we should say that death can be bad for the deceased, despite the impossibility that the deceased experiences it as bad.

Again, an Epicurean could bite the bullet and deny that this case of betrayal is really bad for the one betrayed, but this is very counterintuitive and would imply, as I mentioned above, that many cases in which we ordinarily assume that something is bad for someone (such as certain violations of privacy) would turn out to be different than we thought. An alternative Epicurean strategy is to maintain that there is some relevant difference between the case of death and the other cases considered (such that, while the latter can be bad for the person involved, the former cannot). One way to continue pursuing this strategy is to focus on the fact that, while there is a possible subject of the harm in the betrayal cases, there is no possible subject of the alleged harm in the case of death. This leads us to the next challenge. 


\section{The No-Subject Argument}

The second challenge is also inspired by Epicurus's Letter to Menoeceus:

"Therefore that most frightful of evils, death, is nothing to us, seeing that when we exist death is not present, and when death is present we do not exist. Thus it is nothing to either the living or the dead, seeing that the former do not have it and the latter no longer exist" (Long and Sedley 1987: 150). The passage just quoted is very suggestive and might be read in a number of ways, but there are two interpretations worth considering here (these two interpretations are also discussed in Kagan 2012, chapter 10): first, Epicurus is emphasizing that there is no subject of the harm of death, and thus that death can't be bad (this is the challenge considered in this section); second, Epicurus is emphasizing that there is no time at which death harms anyone, and thus that death can't be bad (this is the challenge considered in the next section).

On the first reading of the passage, Epicurus is claiming that a person must exist in order for anything to be bad for that person. Martha Nussbaum, who has written much on Epicurus and Lucretius and their arguments, has formulated this type of Epicurean argument, the No-Subject Argument, as follows:

1) An event can be good or bad for someone only if, at the time when the event is present, that person exists as a subject of at least possible experience, so that it is at least possible that the person experiences the event.

2) The time after a person dies [that is, death] is a time at which that person does not exist as a subject of possible experience.

3) Hence the condition of being dead [that is, death] is not bad for that person. (Nussbaum 1994: 201-202) 
The No-Subject Argument, just like the No-Harm-Done Argument that we've already considered, is valid; so, in order to respond to the argument, we need to show which premise is false. As with the No-Harm-Done Argument, premise (2) of the No-Subject Argument follows from our assumption about death being a permanent experiential blank; we're assuming that death is the end, so once the deceased is in fact deceased, she no longer exists as the subject of possible experience. Thus, to avoid the Epicurean conclusion, the deprivation account must deny (1).

One way to motivate the denial of (1) is to appeal to examples like the ones considered in the previous section (involving betrayal) and to argue that death is not relevantly different from such cases even though there is no subject of possible experience in the case of death. Consider the following example introduced by Nagel: Suppose an intelligent person receives a brain injury that reduces him to the mental condition of a contented infant, and that such desires as remain to him can be satisfied by a custodian, so that he is free from care. Such a development would be widely regarded as a severe misfortune, not only for his friends and relations, or for society, but also, and primarily, for the person himself. This does not mean that a contented infant is unfortunate. The intelligent adult who has been reduced to this condition is the subject of the misfortune. He is the one we pity, though of course he does not mind his condition - there is some doubt, in fact, whether he can be said to exist any longer. (Nagel 1970: 77)

As with the betrayal cases, it looks as though this case shows that something can be bad for a person even if that person cannot experience the thing as bad. The new case, however, is not very different from the case of death; the intelligent adult who is reduced 
to the mental state of an infant, even if he still exists (which, as Nagel notes, may be doubted), has apparently been harmed in a way that he can no longer appreciate. And since this case is not very different from the case of death, it looks as though the proponent of the deprivation account can maintain that a person need not exist as a subject of possible experience in order to be harmed, which is to say that premise (1) is false.

But, it may be argued, a problem with this new example, as well as the betrayal cases, is that they remain importantly different from the case of death insofar as they involve subjects of possible experience, whereas the deceased is not the subject of possible experience. Indeed, Nussbaum argues that, in the case of the adult whose mental capacity is reduced, "it is hard not to feel that the continued existence of the damaged person, who is continuous with and very plausibly identical with the former adult, gives the argument that the adult has suffered a loss at least a part of its force" (Nussbaum 1994: 206). According to Nussbaum, we simply can't extrapolate from cases involving a subject (like betrayals or cases of mental loss) to the case of death, for it is precisely this feature of death (that there is no subject when it has occurred) that prevents it from being a harm. We could put this Epicurean defense of the No-Subject Argument as follows: the strategy for denying premise (1) that we are considering begins by appealing to a nondeath example of alleged harm and then argues that the case of death is not relevantly different (and so it can harm the deceased); but if the strategy appeals to any example of alleged harm other than death, then there must be a subject of possible experience in that example (since it isn't a case of death); and if there is a subject, then the case is 
importantly different from the case of death (in which there is no subject); so this strategy can't establish that death harms the deceased despite there being no subject.

One way to respond on behalf of the deprivation account is to consider examples in which it is intuitive that, though a person has died (and thus is no longer the subject of possible experiences), something done after that person's death can nevertheless harm them. Imagine that, after a famous author's death, everyone comes to believe (falsely) that her books were written by her brother, who died in Mexico long before the books were published (Nagel 1970: 76). Or, to take a case from Nussbaum's more recent work, in which she makes some concessions concerning such cases:

Suppose that Virgil's Aeneid had been burned at his death (as, in fact, he is said to have requested). Then the posthumous story of Virgil's importance for the whole history of literature, art, and thought would have been completely different. It is not implausible, I think, to view these posthumous events as altering the significance of Virgil's life of striving; that life is now rightly seen as a fantastic success, and some of that achievement consists in altering the way millions of people think about life. (Nussbaum 2013: 33)

As Nussbaum notes, it is not implausible that the significance of Virgil's life would have been affected by the burning of the Aeneid at his death. Moreover, it is not implausible that this would have been bad for Virgil, despite the fact that he would never have experienced anything differently had it happened. Similarly, if an author posthumously loses her fame as a result of widespread false belief about the authorship of her books, this would be bad for that author, despite her nonexistence after her death. If it is true that 
these subject-less cases involve harms, then premise (1) of the No-Subject Argument is false.

At this point, a convinced Epicurean would, of course, deny that there really are any posthumous harms in these cases. From the Epicurean point of view, it makes no difference to Virgil what happens after he dies, for he isn't around to be affected by it! And this leaves us roughly where we started: the Epicurean and the proponent of the deprivation approach simply disagree about the various examples (including the case of death), and it appears that neither side can convince the other to change positions. (This is an instance of what Fischer calls a "dialectical stalemate." For a nice discussion of this dialectical situation, see Fischer 2009, chapter 7.) How should we proceed from here? One way to attempt to make progress would be to consider more examples with the hope of discovering one that will do the trick, convincing the Epicurean that premise (1) of the No-Subject Argument is false. Another way forward is to move on, evaluating other arguments for Epicureanism. Let's proceed in the latter way.

\section{The Timing Argument}

In the previous section, I mentioned that there were two ways to read a certain passage from Epicurus. Here is the passage: "Therefore that most frightful of evils, death, is nothing to us, seeing that when we exist death is not present, and when death is present we do not exist. Thus it is nothing to either the living or the dead, seeing that the former do not have it and the latter no longer exist" (Long and Sedley 1987: 150). We considered the first reading (with an emphasis on there being no subject of death) in the previous section; the second reading has it that Epicurus is emphasizing that there is no 
time at which death harms anyone, and thus that death can't be bad. Following Jens Johansson, we might formulate Epicurus's argument, the Timing Argument, as follows:

1) Anything that is bad for a person is bad for her at a time.

2) There is no time at which death is bad for the person who dies.

3) Hence, death is not bad for the person who dies. (Johansson 2013b: 255)

As with the previous arguments, the Timing Argument is valid. In this case, however, one can resist either premise without giving up any of the assumptions with which we began. On the one hand, one can deny premise (1), claiming instead that death can be bad for a person without being bad for her at a time. This view has been dubbed "atemporalism" (Johansson 2013b). On the other hand, on can deny premise (2), claiming instead that there is a time at which death can be bad for the deceased. Since there are several candidate times for the badness of death, there are several possible ways to reject premise (2) of the Timing Argument. Following Steven Luper, we can identify and label the possible views on the timing of the badness of a person's death as follows: "eternalism" says that death is bad at all times; "subsequentism" says that death is bad after the person has died; "concurrentism" says that death is bad at the time of death (where death is the first moment of the person's nonexistence); and "priorism" says that death is bad before the person dies (Luper 2009). Yet another possible view, endorsed by Nagel, is "indefinitism," according to which the time of the badness of death is indefinite (Luper 2009). Since I don't have the space to evaluate each of these possible responses to the argument here, I will instead focus on Nagel's claims concerning the timing of the harm of death. (For a thorough discussion of the other positions, see Johansson 2013b.) 
Recall the case we considered in the previous section involving an intelligent adult who is (tragically) reduced to the mental state of an infant. Concerning this case, Nagel says:

This case should convince us that it is arbitrary to restrict the goods and evils that can befall a man to nonrelational properties ascribable to him at particular times. As it stands, that restriction excludes not only such cases of gross degeneration, but also a good deal of what is important about success and failure, and other features of a life that have the character of processes. I believe we can go further, however. There are goods and evils which are irreducibly relational; they are features of the relations between a person, with spatial and temporal boundaries of the usual sort, and circumstances which may not coincide with him either in space or in time. A man's life includes much that does not transpire within the boundaries of his body and his mind, and what happens to him can include much that does not take place within the boundaries of his life. These boundaries are commonly crossed by the misfortunes of being deceived, or despised, or betrayed. (If this is correct, there is a simple account of what is wrong with breaking a deathbed promise. It is an injury to the dead man. For certain purposes it is possible to regard time as just another type of distance.) (Nagel 1970: 77-78)

It is relatively simple, according to Nagel, to determine the boundaries, both spatial and temporal, of a human being. Still, Nagel thinks, much of a person's life, including what happens to the person, lies outside of those boundaries. Much of Virgil's life, for example, depended on his Aeneid not being burned upon his death; in fact, the event of Virgil's wishes being ignored (concerning the burning of his Aeneid) is something that 
happened to Virgil, despite the fact that this event occurred outside the temporal boundaries of Virgil's life. As Nagel puts it, we can think of cases in which some later event affects the deceased (either by harming or benefitting the deceased) as instances of temporal distance. Just as I can be harmed by an event that occurs spatially distant from me (such as when my bicycle is stolen while I am away), so too, on Nagel's view, I can be harmed by an event that occurs at some temporal distance from me.

Talk of temporal distance might suggest subsequentism about the timing of death's badness (the view that death harms the deceased after her death), but Nagel's view is that the harm does not have so specific a temporal location even if both the person harmed and the event that brings about the harm (death) do have specific temporal locations. (For an endorsement of subsequentism that makes reference to temporal distance, though, see Fischer 2009, chapter 3.) According to Nagel:

When a man dies we are left with his corpse, and while a corpse can suffer the kind of mishap that may occur to an article of furniture, it is not a suitable object for pity. The man, however, is. He has lost his life, and if he had not died, he would have continued to live it, and to possess whatever good there is in living...[A]lthough the spatial and temporal locations of the individual who suffered the loss are clear enough, the misfortune itself cannot be so easily located. One must be content just to state that his life is over and there will never be any more of it. That fact, rather than his past or present condition, constitutes his misfortune, if it is one. Nevertheless if there is a loss, someone must suffer it, and he must have existence and specific spatial and temporal location even if the loss itself does not. (Nagel 1970: 78) 
The harm (or misfortune) of death, on Nagel's view, need not have a specific spatiotemporal location in order to be a genuine harm to the deceased. In other words, we may not be able to pinpoint the exact temporal location of death's harm to the deceased, but we can nevertheless maintain that death is a harm to the deceased despite the fact that the event of death (which results in the harm) is temporally distant from the deceased. Thus, on Nagel's view, premise (2) of the Timing Argument is false; even if the timing of the harm of death is indeterminate, it does not follow that there is no time at which death harms the deceased.

\section{The Symmetry Argument}

Even if each of the challenges that we've considered can be met, however, the one that remains to be considered is perhaps the most difficult challenge for the deprivation account. This last challenge is suggested by Lucretius in his De Rerum Natura:

Look back now and consider how the bygone ages of eternity that elapsed before our birth were nothing to us. Here, then, is a mirror in which nature shows us the time to come after our death. Do you see anything fearful in it? Do you perceive anything grim? Does it not appear more peaceful than the deepest sleep? $(D R N$ 972-977, trans. Martin Ferguson Smith)

According to Lucretius, there is a certain symmetry between the time before we exist (which we can call our prenatal, or pre-vital, nonexistence) and the time after we exist (which we can call our posthumous nonexistence, or simply death); in both cases, we do not exist. But, Lucretius argues, since there is nothing grim about our prenatal nonexistence, and since our posthumous nonexistence is not relevantly different, we should have the same view of our posthumous nonexistence. (Note that, while Lucretius 
seems primarily concerned with whether or not we should fear death, I have been setting aside questions about the fear of death in this chapter to focus on whether death can be bad. These sets of questions are related, to be sure, and answers to one set of questions may be relevant to the other set, but we can keep them separate for our purposes here and consider a version of Lucretius's argument that focuses on death's badness.) We could articulate Lucretius's argument, the Symmetry Argument, as follows:

1) Prenatal nonexistence is not bad for the person who comes into existence.

2) There is no relevant difference (with respect to badness) between prenatal nonexistence and posthumous nonexistence (death).

3) Thus, death is not bad for the one who dies.

On my view, the Symmetry Argument is the most interesting and challenging weapon in the Epicurean arsenal. Both of the premises are very plausible, and the inference from those premises to the conclusion appears valid. How might a proponent of the deprivation account respond to the Symmetry Argument?

One possible response is to reject premise (1), thereby accepting the counterintuitive position that prenatal nonexistence is bad for the person who comes into existence. Fred Feldman commends this approach:

There are, after all, two ways in which we can rectify the apparently irrational emotional asymmetry. On the one hand, we can follow Lucretius and cease viewing early death as a bad thing for [the deceased]. On the other hand, we can at least try to start viewing late birth as a bad thing. My suggestion is that in the present case, the latter course would be preferable. (Feldman 1991: 223) 
If one accepts premise (2) of the Symmetry Argument, one could nevertheless reject the Epicurean conclusion that death can't harm the deceased. The catch, of course, is that doing so while maintaining (2) requires accepting, as Feldman does, that our prenatal nonexistence is bad for us. On this approach, one denies both premise (1) and the conclusion (3) of the Symmetry Argument. While I don't have a knockdown argument against this approach, I find it difficult to accept that my own prenatal nonexistence is bad for me. Hence, I'm motivated to look elsewhere for a response to the argument. On my view, a more promising response to the Symmetry Argument is to argue that there is some asymmetry overlooked by the argument and thus that, in fact, premise (2) is false. In particular, a proponent of the deprivation account could argue that death deprives us of something which prenatal nonexistence does not. This is how Nagel responds to the Symmetry Argument:

It is true that both the time before a man's birth and the time after his death are times when he does not exist. But the time after his death is time of which his death deprives him. It is time in which, had he not died then, he would be alive... But we cannot say that the time prior to a man's birth is time in which he would have lived had he been born not then but earlier. For aside from the brief margin permitted by premature labor, he could not have been born earlier: anyone born substantially earlier than he was would have been someone else. Therefore the time prior to his birth is not time in which his subsequent birth prevents him from living. (Nagel 1970: 79)

Nagel's suggestion is that, while death can deprived the deceased of goods (and thereby harm the deceased), prenatal nonexistence does not deprive anyone of any goods, since 
anyone who was born earlier enough to receive any extra goods would not be the same person. On Nagel's view, then, there is an important asymmetry between prenatal and posthumous nonexistence; if prenatal nonexistence were to end earlier (that is, if one came into existence earlier), it would be a different person that came into existence, whereas if posthumous nonexistence were to begin later (that is, if a person were to die later), it would be the same person who would be able to enjoy more goods of life. Thus, Nagel thinks, one can accept premise (1) of the Symmetry Argument (which says that prenatal nonexistence is not bad) without accepting the Epicurean conclusion that death can't be bad for the deceased.

A common objection to Nagel's suggestion is that it depends on the claim that it is not possible for a person to come into existence earlier than that person actually comes into existence. This apparently relies on a strict version of what is sometimes called an "essentiality of origins" thesis, according to which it is essential to a person that she develops from a particular fertilized egg that comes into existence at a particular timeany other fertilized egg, or the same fertilized egg but that came into existence at any other time, would necessarily be a different person, on this view. I find this strict essentiality of origins thesis incredibly implausible, and (perhaps unsurprisingly) it is very controversial. Consider a case suggested by Fischer: a fertilized egg is frozen and thawed out at a later time (many years later, say). For the individual who develops from this fertilized egg, it was possible that she be born earlier, since she could have been thawed out sooner (Fischer 2009: 65-66). Nagel himself confesses to being troubled by his response to the Symmetry Argument, partly because of this kind of worry. When his essay was reprinted in his book Mortal Questions, he added a footnote to suggest a 
different response: "I suspect that [a response to the Symmetry Argument] requires a general treatment of the difference between past and future in our attitudes toward our own lives. Our attitudes toward past and future pain are very different, for example. Derek Parfit's writings on this topic have revealed its difficulty to me" (Nagel 1979: 9). Rather than attempting to show that it isn't possible to be born earlier, as he had suggested at first, Nagel's second suggestion, inspired by Parfit, is that we look for an asymmetry in our attitudes toward past and future events in order to explain how the Symmetry Argument fails.

So, Nagel has provided two suggestions for responding to the Symmetry Argument, the first of which, as he acknowledges, faces some difficulties, and the second of which he leaves to be developed. In the remainder of this chapter, I want to explore a recent development of each of Nagel's two suggestions. The first suggestion, according to which it isn't possible to be born earlier, is defended (after some modification) by Frederik Kaufman (Kaufman 1999). The second suggestion, according to which there is an important asymmetry in our attitudes toward the past and future, is developed and defended by Anthony Brueckner and John Martin Fischer (Brueckner and Fischer 1986; Fischer and Brueckner 2012). Let's consider each in turn.

While Kaufman endorses the criticisms of Nagel's first suggestion discussed above, he nevertheless claims that there is a sense in which it is not possible for us to be born substantially earlier than we are in fact born. To see why this is the case, Kaufman thinks, we need to distinguish between two senses of the term person (Kaufman 1999: 11-12). On the one hand, person might refer to a person in the "thin" sense, which picks out the metaphysical essence of some human being, whatever that may be (perhaps a 
certain soul, or a brain, or some such). On the other hand, person might refer to a person in the "thick" sense, which picks out one's subjective sense of self, including one's psychological features (such as memories and character traits). Crucially, a person in the "thin" sense could have lived a very different life and thus been a different person in the "thick" sense; if someone were to have a very different history, with the result that she would have a very different psychological makeup, she would not be the same person in the "thick" sense.

How is the distinction between "thin" and "thick" persons relevant to the Symmetry Argument? Well, on Kaufman's view, the reason that death can harm the deceased is that it can deprive a person, construed in the "thick" sense, of various goods; but, according to Kaufman, it isn't possible for prenatal nonexistence to deprive a person, construed in the "thick" sense, of any goods (Kaufman 1999: 12-14). If someone were to be born earlier, the result would be a very different "thick" person with a new history, different memories, and perhaps even an unfamiliar character. (This is the sense in which Kaufman thinks that it isn't possible to be born substantially earlier than we are in fact born.) By contrast, a "thick" person can always, as it were, get "thicker" by accruing new psychological features without a loss to what was already part of her "thick" self. So, on Kaufman's view, prenatal nonexistence is not bad for us (construed as "thick" persons), but death can be bad for us insofar as it deprives us (again, construed as "thick" persons) of various goods. Thus, according to Kaufman, premise (2) of the Symmetry Argument is false - there is an asymmetry concerning the badness of the prenatal and posthumous nonexistence of "thick" persons. 
Before we turn to Nagel's second suggestion, as developed by Brueckner and Fischer, let me mention just one difficulty for Kaufman's version of Nagel's first suggestion. Kaufman's proposal can only succeed if the only deprivations that matter to us are deprivations of goods for the "thick" persons that we currently are. Kaufman thinks that these are, in fact, the deprivations we care about, and this is why he thinks that only posthumous (and not prenatal) deprivations can be bad for us. But it is not clear that Kaufman is right about this, as it is a very commonplace occurrence for a person to regret a past deprivation that would have resulted, had it occurred, in a different "thick" person, with various changes to that person's psychological features. Some children, to take just one example, are deprived of a good education, and this can be bad for the children so deprived even if they would have been different "thick" persons had they received a better education. (For discussion of similar cases, see Fischer 2009, chapter 5.) For this reason, I am skeptical that it is merely our "thick" selves that we care about when thinking of past and future deprivations. Perhaps we also care about whether our "thin" selves are associated with particular "thick" selves.

An alternative response to the Symmetry Argument takes Nagel's second suggestion and attempts to show that some asymmetry in our attitudes toward past and future events justifies our view that death, but not prenatal nonexistence, can be bad for us. Nagel notes that Parfit's writings on this subject revealed its difficulty to him, and it turns out that Parfit's writings also played a part in Brueckner and Fischer's development of Nagel's suggestion. On Parfit's view, we prefer to have our sufferings in our past rather than in our future, and it is not obviously irrational for us to regard our past and future sufferings asymmetrically. Brueckner and Fischer argue that, while Parfit is right 
about the asymmetry in our attitudes toward past and future events, the asymmetry concerning sufferings is not sufficient to provide an adequate response to the Symmetry Argument - in particular, they worry that Parfit's approach will only apply to bads that are experienced as bad (like suffering), which will not apply to the case of death (Brueckner and Fischer 1986: 216). Instead, they argue, we need to focus on our attitudes toward past and future goods (Brueckner and Fischer 1986: 219).

In their first article on the subject, Brueckner and Fischer's thesis was that “[d]eath deprives us of something we care about, whereas prenatal nonexistence deprives us of something to which we are indifferent" (Brueckner and Fischer 1986: 219). They give the following thought experiment, inspired by some of Parfit's examples (see Parfit 1984), to highlight our actual asymmetric attitudes toward past and future goods (such as pleasures):

Imagine that you are in some hospital to test a drug. The drug induces intense pleasure for an hour followed by amnesia. You awaken and ask the nurse about your situation. She says that either you tried the drug yesterday (and had an hour of pleasure) or you will try the drug tomorrow (and will have an hour of pleasure). While she checks on your status, it is clear that you prefer to have the pleasure tomorrow. (Brueckner and Fischer 1986: 218-219)

As this case shows, we prefer to have pleasures in our future rather than in our past. According to Brueckner and Fischer, this is why we regard death as a harm to the deceased but do not regard prenatal nonexistence as bad for anyone; death can deprive us of future goods, whereas prenatal nonexistence deprives us of goods to which we are indifferent. 
So far, however, Lucretius (and other Epicureans) can agree with Brueckner and Fischer. It may be the case, Lucretius could say, that we actually have a preference for future goods over past goods, but that doesn't show that it is rational for us to have such preference patterns. And if it isn't rational for us to have such preference patterns, then it looks like the Symmetry Argument is untouched by the Brueckner/Fischer approach. In response to this and related worries (some raised by Feldman 2011 and Johansson 2013a; 2014), Fischer and Brueckner have added a "rationality component" to their view:

“Although we originally put our point in terms of what we took to be people's actual preference patterns, we should have put it in terms of the rationality of such patterns of preference" (Fischer and Brueckner 2014: 3; see also Fischer and Brueckner 2012). Rather than relying on the asymmetry of the preference patterns with which we happen to find ourselves, Fischer and Brueckner maintain that these asymmetrical patterns are actually rational for us to have and thus that it is rational for us to regard death as a harm to the deceased (since the deceased is deprived of future goods that it is rational to care about) without regarding prenatal nonexistence as a similar harm (since it deprives us of something it is not rational to care about). And this allows Fischer and Brueckner to deny premise (2) of the Symmetry Argument — even though both prenatal and posthumous nonexistence can deprive a person of goods, only posthumous nonexistence (that is, death) can deprive a person of goods that it is rational to care about, and thus death, but not prenatal nonexistence, can harm the deceased. Despite the apparent complexity in their approach, I am inclined to think that Fischer and Brueckner's account best captures our ordinary way of thinking about the way that death can harm the deceased. 


\section{Conclusion}

As I hope it is clear from this chapter, it is actually quite challenging to defend the very natural view that it is possible for death to harm the deceased, assuming that death is the end. Given the challenges, one starts to see the attractions of the Epicurean view that it isn't possible for death to harm the deceased. Still, as we have seen, there are ways to resist the Epicurean arguments, and I have surveyed Nagel's influential responses to each of the Epicurean challenges he considered in his classic essay on the topic. Whether or not such resistance is ultimately successful remains, in my view, one of the most interesting debates in contemporary philosophy.

\section{Related Topics}

Chapter 1, "Death, Personhood, and Moral Standing” by John K. Davis Chapter 12, "The Severity of Death" by Jens Johansson Chapter 13, "The Significance of an Afterlife" by Benjamin Mitchell-Yellin Chapter 15, "Is Extended Life Good for You?" by Rosa Rantanen

\section{References}

Bradley, B. (2009) Well-Being and Death, New York: Oxford University Press. Brueckner, A.L., and Fischer, J. M. (1986) "Why Is Death Bad?" Philosophical Studies 50: 213-221. Reprinted in J. M. Fischer (ed.) The Metaphysics of Death, Stanford: Stanford University Press, 1993: 221-229.

Feldman, F. (1991) "Some Puzzles About the Evil of Death," The Philosophical Review 100 (2): 205-227. Reprinted in J. M. Fischer (ed.) The Metaphysics of Death, Stanford: Stanford University Press, 1993: 307-326.

Feldman, F. (1992) Confrontations with the Reaper: A Philosophical Study of the Nature and Value of Death, New York: Oxford University Press.

Feldman, F. (2011) "Brueckner and Fischer on the Evil of Death," Philosophical Studies 162: 309-312.

Fischer, J. M. (2009) Our Stories: Essays on Life, Death, and Free Will, New York: Oxford University Press.

Fischer, J. M. (2014) "Mortal Harm," in S. Luper (ed.) The Cambridge Companion to Life and Death, Cambridge: Cambridge University Press, 2014: 132-148.

Fischer, J. M. and Brueckner A. L. (2012) "The Evil of Death and the Lucretian Symmetry: A Reply to Feldman," Philosophical Studies 163: 783-789.

Fischer, J. M. and Brueckner, A. L. (2014) "Prenatal and Posthumous Non-Existence: A Reply to Johansson," The Journal of Ethics 18: 1-9. 
Johansson, J. (2013a) "Past and Future Non-Existence," The Journal of Ethics 17: 5164.

Johansson, J. (2013b) “The Timing Problem," in B. Bradley, F. Feldman, and J. Johansson (eds.) The Oxford Handbook of Philosophy of Death, New York: Oxford University Press, 2013: 255-273.

Johansson, J. (2014) "Actual and Counterfactual Attitudes: Reply to Brueckner and Fischer," The Journal of Ethics 18: 11-18.

Kagan, S. (2012) Death, New Haven: Yale University Press.

Kaufman, F. (1999) "Pre-Vital and Post-Mortem Non-Existence," American Philosophical Quarterly 36 (1): 1-19.

Long, A. A. and Sedley, D. N. (1987) The Hellenistic Philosophers (vol. 1), Cambridge: Cambridge University Press.

Luper, S. (2009) "Death," in E. N. Zalta (ed.) The Stanford Encyclopedia of Philosophy (Winter 2014 Edition), URL = $<$ http://plato.stanford.edu/archives/win2014/entries/death/>.

Nagel, T. (1970) "Death," Nous 4 (1): 73-80. Reprinted in his Mortal Questions, Cambridge: Cambridge University Press, 1979: 1-10. Reprinted in J. M. Fischer (ed.) The Metaphysics of Death, Stanford: Stanford University Press, 1993: 61-69.

Nozick, R. (1999) “On the Randian Argument," in his Socratic Paradoxes, Cambridge: Harvard University Press, 1999: 249-264.

Nussbaum, M. (1994) The Therapy of Desire: Theory and Practice in Hellenistic Ethics, Princeton: Princeton University Press.

Nussbaum, M. (2013) "The Damage of Death: Incomplete Arguments and False Consolations," in J. S. Taylor (ed.) The Metaphysics and Ethics of Death: New Essays, New York: Oxford University Press, 2013: 25-43.

Parfit, D. (1984) Reasons and Persons, Oxford: Clarendon Press.

\section{Further Reading}

Bradley, B., Feldman, F., and Johansson, J., (eds.). (2013) The Oxford Handbook of Philosophy of Death, New York: Oxford University Press. (This is a recent collection of essays on the philosophy of death, with articles dedicated to the "Timing Argument" and "Symmetry Argument" discussed in this chapter.)

Fischer, J. M., (ed.). (1993) The Metaphysics of Death, Stanford: Stanford University Press. (This is a collection of the classic papers on the philosophy of death, with several articles on the badness of death and a very helpful introduction, by Fischer, to the philosophical issues at play in the literature.)

Kagan, S. (2012) Death, New Haven: Yale University Press. (This book is an excellent introduction to thinking about death; it is a very enjoyable read, and it provides some metaphysical background for questions about death's badness.)

Nagel, T. (1970) "Death," Nous 4 (1): 73-80. Reprinted in his Mortal Questions, Cambridge: Cambridge University Press, 1979: 1-10. (This short paper, which I've referenced through the current chapter, is at least partly responsible for getting contemporary philosophers talking about death's badness, and it is a mustread for anyone interested in the topic.) 